\title{
Introducing Ductile Strip for Durability Enhancement of Concrete Slabs
}

\author{
Jun Zhang'; Victor C. Li, F.ASCE'; Andrzej S. Nowak, F.ASCE ${ }^{3}$; and Shuxin Wang ${ }^{4}$
}

\begin{abstract}
This paper presents an experimental study on the potential applications of the fiber-reinforced engineered cementitious composite (ECC) in concrete slabs, such as concrete bridge decks and pavements. It is recognized that cracking due to concrete shrinkage and temperature gradient in the transverse direction in concrete slabs strongly influences the fatigue service life of the slabs. In the present study, attempts at localizing cracks, especially shrinkage cracks, into designated strips, where ECC material with strain-hardening and high strain capacity (up to 5\%) and high fatigue crack resistance behavior is used, were carried out. As a result, while microstructure damage exists in the ECC strip, the concrete remains intact. This is demonstrated by simulating the shrinkage in concrete under restrained conditions as tensile load acting on a specially designed specimen. Experimental results show that it is possible to achieve the targeted deformation mode with a certain design on the ECC/concrete interfaces and a certain curing period on the ECC-concrete composite slab. Due to the special material properties of ECC, the strain energy produced by shrinkage (under restrained conditions) of hardened cement and temperature changes can be released by the high strain ability of ECC material so that cracking in plain concrete can be avoided. Thus, the fatigue durability of concrete slabs can be improved, resulting in a longer service life. The proposed design concept may be implemented by placing ECC as periodic special joints or "ductile strip" between stretches of concrete slabs. By replacing standard joints, common deterioration (e.g., D-cracking) problems associated with joints may be also eliminated.
\end{abstract}

DOI: 10.1061/(ASCE)0899-1561(2002)14:3(253)

CE Database keywords: Concrete slabs; Durability; Stripping; Cracking; Strain hardening.

\section{Introduction}

Reinforced concrete slabs have been widely used in modern transportation engineering, such as highway and airport pavements and bridge decks. The average life of a concrete slab is determined by many factors, including initial design details, material properties, traffic load and frequency, environment, salt application, presence and effectiveness of protective systems, and maintenance practices, among others. All these factors influence the development of cracks in slabs during service. Cracking in slabs reduces the load capacity and has been linked to fatigue failure (Perdikaris and Beim 1988; Perdikaris et al. 1989; Matsui 1997; Kumar and GangaRao 1998). In addition, cracks allow water and other chemical agents, such as deicing salt, to go through the cover layer and come into contact with the reinforcements, leading to reinforcement corrosion and rupture.

\footnotetext{
${ }^{1}$ Associate Professor, Dept. of Civil Engineering, Tsinghua Univ., Beijing 100084, P. R. China.

${ }^{2}$ Professor and Director, ACE-MRL, Dept. of Civil and Environmental Engineering, Univ. of Michigan, Ann Arbor, MI 48109.

${ }^{3}$ Professor, Dept. of Civil and Environmental Engineering, Univ. of Michigan, Ann Arbor, MI 48109.

${ }^{4}$ Research Assistant, ACE-MRL, Dept. of Civil and Environmental Engineering, Univ. of Michigan, Ann Arbor, MI 48109.

Note. Associate Editor: Christopher K.Y. Leung. Discussion open until November 1, 2002. Separate discussions must be submitted for individual papers. To extend the closing date by one month, a written request must be filed with the ASCE Managing Editor. The manuscript for this paper was submitted for review and possible publication on June 19, 2000; approved on March 14, 2001. This paper is part of the Journal of Materials in Civil Engineering, Vol. 14, No. 3, June 1, 2002. (CASCE, ISSN 0899-1561/2002/3-253-261/\$8.00+\$.50 per page.
}

Deterioration of concrete slabs is a common cause requiring repair, rehabilitation, or replacement of pavement and bridge structures. Therefore, innovative technology for repair and for new construction of concrete slabs is urgently needed.

The deterioration of concrete slab is caused by concrete shrinkage, temperature changes, freeze and thaw cycles, and repeated loading. The various stages of concrete slab deterioration (Szerszen et al. 1999) may be summarized as follows:

1. Initial cracks due to shrinkage and temperature change: Concrete shrinks as the cement paste hardens. The value of shrinkage can be reduced by using concrete with the smallest possible amount of water and cement compatible with other requirements, such as strength and workability, and by moist-curing for sufficient duration. However, no matter what precautions are taken, a certain amount of shrinkage is usually unavoidable. If a slab of moderate dimension rests freely on its supports, it can contract to accommodate the shortening of its length produced by shrinkage. Usually, however, slabs and other members are jointed rigidly to other parts of the structure (i.e., top flange of girders in bridge and base in pavement) and cannot contract freely. This results in tensile stress known as shrinkage stresses. A change in temperature may have an effect similar to shrinkage, which also results in stresses in the slab, increasing temperature results in compressive stress and decreasing temperature results in tensile stress.

As the tensile stress produced by shrinkage and temperature attains the tensile strength of material, concrete cracks. These cracks typically occur on both top and bottom faces of a slab in a transverse direction to traffic.

2. Formation of through-thickness traverse cracks: These transverse cracks are subjected to freeze and thaw cycles. For 
example, in Michigan there are about 10 freeze-thaw cycles per year. Freezing water expends, and this results in additional damage, an increase of crack width and depth. Cracked slab surface is linearable to touch traffic loads. Each passage of a heavy wheel may cause a strain/stress concentration which leads to further cracking and disintegration of the slabs. In addition, further development of concrete shrinkage or temperature change also leads to the growth of the transverse cracks. These factors working together lead to the formation of through-thickness cracks.

Water, particularly water containing chlorides (salt used as a deicing agent), penetrates the cracks and, when it reaches the reinforcing steel, may cause corrosion. Corroded steel expands, which results in additional cracking and disintegration of cracked slabs.

3. Water penetration and wearing out of the through cracks: Water gradually moves downward through the cracks, creating efflorescence on the bottom surface of the slab. Under repeated traffic load, the through crack faces are gradually worn out, leading to the loss of load distribution in the longitudinal direction. As a result, the slab does not behave as a plate any longer, but acts as transverse beam. The presence of water accelerates the wearing out procedure. In addition, when the water, in particular that containing chlorides (salt used as a deicing agent), reaches the reinforcing steel, it may cause corrosion. Corroded steel expands, which results in additional cracking and disintegration of cracked slabs.

4. Slab failure in shear, delamination and spalling: Finally, passages of truck wheels on the cracked slabs result in formation of potholes, delamination, spalling, and reducing and/or terminating the ability to carry traffic.

The deterioration stages summarized above indicate that, in reinforced concrete slabs, the initial shrinkage cracking and subsequent through slab-thickness crack propagation under repeated traffic load are the principle reasons for limiting the service life of the structures. Fatigue durability is as important as corrosion durability in governing slab service life. Furthermore, previous investigations (Matsui 1997) show that the integrity of steel reinforced concrete bridge decks is the key for improving the durability of bridges. Therefore, the prevention of fatigue failure in reinforced concrete slabs is crucial, and the sequence of the four stages described above has to be interrupted before final deck failure. Hence, reducing shrinkage cracks and enhancing fatigue crack growth resistance of the material become critical objectives to prolong the service life of steel reinforced concrete slabs.

In the present study, an attempt at localizing cracks, especially shrinkage cracks, into designated ductile strips is investigated. In these strips between regular concrete slabs, a special kind of fiber-reinforced cementitious composite, with strain-hardening and high strain capacity and high fatigue crack resistance as compared with concrete, is applied. Shrinkage tensile stresses induce microcrack damage in these strips. To implement this concept, an engineered cementitious composite (ECC) with 5\% tensile strain capacity is selected. The strain energy produced by shrinkage (under restrained conditions) of hardened cement and temperature gradient can be released by the high deformation within the ECC material; therefore, cracking in concrete can be avoided. Thus, the fatigue durability of concrete slabs can be improved, resulting in a longer service life.

\section{Material Properties}

To realize the above design concept, the tensile properties of both concrete and ECC material must be carefully tailored. This sec-
Table 1. Properties of Fiber used in this Study

\begin{tabular}{lcccc}
\hline Type & $\begin{array}{c}E_{f} \\
(\mathrm{GPa})\end{array}$ & $\begin{array}{c}\sigma_{f} \\
(\mathrm{MPa})\end{array}$ & $\begin{array}{c}d_{f} \\
(\mathrm{~mm})\end{array}$ & $\begin{array}{c}L_{f} \\
(\mathrm{~mm})\end{array}$ \\
\hline Polyethylene & 120 & 2,700 & 0.038 & 19.05
\end{tabular}

Note: $E_{f}=$ fiber modulus; $\sigma_{f}=$ fiber tensile strength; $d_{f}=$ fiber diameter; $L_{f}=$ fiber length.

tion describes the tensile behavior of plain concrete and ECC. Because of the different time dependence of strength development in ECC and concrete, the curing time effect will be focused on in this study. The principles of inserting a plastic strip in continuous reinforced concrete slabs will be described in the following.

\section{Engineered Cementitious Composite Material Performance under Uniaxial Tension}

ECC is a cement based composite reinforced with a low volume percentage (usually less than $2-3 \%$ ) of short, randomly oriented fibers. The composite has been microstructurally engineered to strain-harden via multiple cracking in uniaxial tension (Li 1993, 1998). ECC exhibits macroscopic strain-hardening after the first crack. For the ECC containing polyethylene (PE) fibers used in this study, strain at its peak load at 28 days is approximately $5 \%$, as compared with $0.01-0.02 \%$ tensile strain capacities in regular concrete. During strain-hardening, multiple cracks develop with continuously reducing crack spacing until localization occurs at one of these cracks. The fracture site is not necessarily the first crack site. The evolution of multiple cracking appears to be a stochastic process associated with distributed initial flaw sizes (Wu and $\mathrm{Li} \mathrm{1995).} \mathrm{In} \mathrm{this} \mathrm{study,} \mathrm{the} \mathrm{tensile} \mathrm{behavior} \mathrm{of} \mathrm{ECC}$ material under different curing period is investigated. The details of the experiments are described below.

\section{Materials, Specimens, and Mixing Procedures}

In the present investigation, type I ordinary portland cement and silica sand with an approximate particle size of $0.1-0.3 \mathrm{~mm}$ were used to form the matrix. Polyethylene fiber (Spectra 900) was employed and the fiber properties are listed in Table 1. Mix proportions adopted in this study are given in Table 2 . The tensile specimen is in the form of a rectangular coupon of size 304.8 $\times 76.2 \times 12.7 \mathrm{~mm}$. The molds used to cast the specimens were made of plexiglass. The mixing procedure of the composite material consists of the following steps:

1. Matrix preparation: The matrix was prepared in a Hobart type mixer. First, the cement and silica sand were mixed together for $2 \mathrm{~min}$ at low speed. Then, water with superplas-

Table 2. Mix Proportions of Plain Concrete and Engineered Cementitious Composite (ECC)

\begin{tabular}{lcc}
\hline Components & PC & ECC \\
\hline Cement & 0.9 & 1 \\
Silica fume & 0.1 & - \\
Sand & 1.62 & 0.5 \\
Stone & 1.62 & - \\
Water & 0.31 & 0.32 \\
Superplasticizer & 0.027 & 0.02 \\
Methyl cellulose & - & 0.0007 \\
Antifoamer & - & 0.0005 \\
Spectra fiber & - & $1.5 \%$ in volume \\
\hline
\end{tabular}

${ }^{\mathrm{a}}$ Water content in superplasticizer is $66 \%$. 


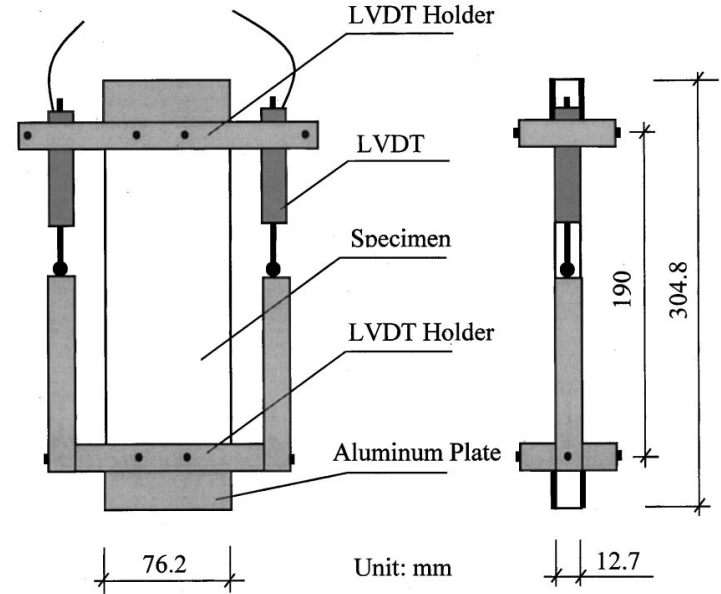

Fig. 1. Test setup of engineered cementitious composite in tension

ticizer (polymelamine) and a viscous agent (methyl cellulose) mixed in were gradually added, and mixing was continued for $2 \mathrm{~min}$, resulting in a uniform fluid matrix. Within this period, the bottom of the mixing bowl should be scraped manually to ensure that no solid materials stick to the bottom. After such scraping, the matrix was mixed at a higher speed for $1 \mathrm{~min}$ before addition of fibers.

2. Addition of fibers: The fibers were gradually spread into the mixer by hand as the matrix was mixed at a slow speed. The fibers must be added slowly to ensure proper distribution with no fibers bundled together.

3. Casting and curing: The composite material was carefully cast into the mold in two layers. First, about half the material was placed. Then the mix was vibrated for about 1-2 min to ensure that the material was well compacted. Next, the second half of the mold was filled by the composite in the same manner. After smoothing the surface, the specimens were covered with a polyethylene sheet to prevent loss of moisture and stored for $24 \mathrm{~h}$ at room temperature prior to demolding. Then all specimens were removed from their molds and put into water at $23^{\circ} \mathrm{C}$ for curing until tensile testing was carried out.

\section{Testing Procedures}

The specimens were tested in uniaxial tension with displacement control in a $250 \mathrm{kN}$ capacity MTS 810 material testing system with hydraulic wedge grips. Aluminum plates were epoxy glued onto the ends of the specimens to enhance the ends for gripping. The actuator displacement rate used for controlling the test was $0.0025 \mathrm{~mm} / \mathrm{s}$. The strain was measured by two linear variable differential transducers (LVDTs) mounted on the surface of the specimen. The measured gauge length of LVDTs was $190 \mathrm{~mm}$. The specimen with LVDTs mounted is shown in Fig. 1 ( $\mathrm{Li}$ et al. 1996). The raw data consisted of time, load, position of the piston, and displacement from each LVDT. The tensile behavior can then be determined from these test data.

\section{Test Results of Engineered Cementitious Composite in Tension}

The typical uniaxial tensile test results, in terms of stress-strain diagrams, with different curing periods from 3 to 28 days are shown in Fig. 2. The typical crack patterns at 21 days and 28 days are shown in Fig. 3. The corresponding first cracking strength and the ultimate tensile strength as well as the corresponding strain level are listed in Table 3. From these experimental results, first we can see that the strength development of ECC material, including both the first cracking strength and the ultimate tensile strength, is characterized by a fast development period, around 3 days, which is the minimum curing time in the present study, followed by a relative slow development period, as shown in Fig. 4. Second, the ECC material already starts to show significant multiple cracking and strain-hardening behavior at 3 days water curing, even though the minimum critical curing time for this behavior still needs to be determined. These results are consistent with the single fiber pullout results (Chan and Li 1997), which indicate the saturated bond strength of polyethylene spectra fiber and cement matrix can be achieved approximately 2 days after casting. The first crack strength and ultimate tensile strength slightly increase with curing time due to the development of cement hydration and its influence on the frictional stress between fiber and matrix. However, the rate of increase is lower than that of the plain concrete, which will be demonstrated in the next section.

\section{Strength Development of Plain Concrete under Uniaxial Tension}

\section{Materials, Specimen, and Test Procedure}

In order to study the tensile strength development of concrete with curing time, a loading holder (Fig. 5) used for studying the cracking behavior of ECC (Kanda and Li 1998) was adopted. The holders were made of aluminum alloy. One was fixed to the load cell and the other to the actuator with standard MTS grips. The tensile load was transmitted to the specimen by the anchor action between holders and the enlarged ends of the specimen. To further prevent failure due to stress concentration at the loaded ends of the concrete specimens, two steel bolts with a $6 \mathrm{~mm}$ diameter and a $12 \mathrm{~mm}$ length were used to reinforce the specimen ends. One end of each bolt was connected with a nut and the other end was fastened to a $118 \times 45 \times 7 \mathrm{~mm}$ steel plate through another nut. Thus, the failure of the specimen under tensile load can be ensured to be within the central position with a uniform cross section. The minimum cross section of the specimen was 76 $\times 45 \mathrm{~mm}$. The overall uniaxial tensile strain was measured with two LVDTs, one on each side of the specimen. The details of the experimental setup and the geometry of the test specimen are shown in Fig. 5.

In the present investigation, type I ordinary portland cement and silica fume, natural sand with an approximate particle size of 0.3-4 mm, and crushed natural stone with a maximum particle size of $10 \mathrm{~mm}$ were used. The mix proportions are given in Table 3. The casting and curing procedures are similar to the ECC specimens.

All tests were carried out under displacement control with a prescribed rate of $0.005 \mathrm{~mm} / \mathrm{s}$ in a $250 \mathrm{kN}$ capacity MTS 810 material testing system.

\section{Experimental Results and Discussions}

The tensile strength of concrete at different curing time is listed in Table 3. The tensile strength versus curing period diagram is shown in Fig. 4. By comparing the results between plain concrete and ECC, it can be found that at 3 days curing, there is almost no difference between plain concrete and ECC on the first cracking strength. However, after 3 days, the tensile strength of concrete develops at a faster rate than that of ECC, probably due to the contribution of the coarse aggregates. The tensile strength of concrete starts to overtake the first cracking strength of the ECC 


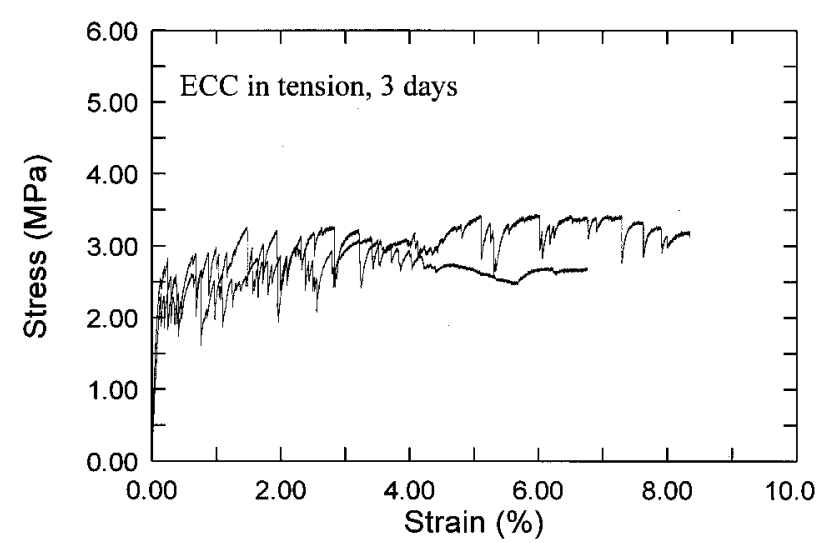

(a)

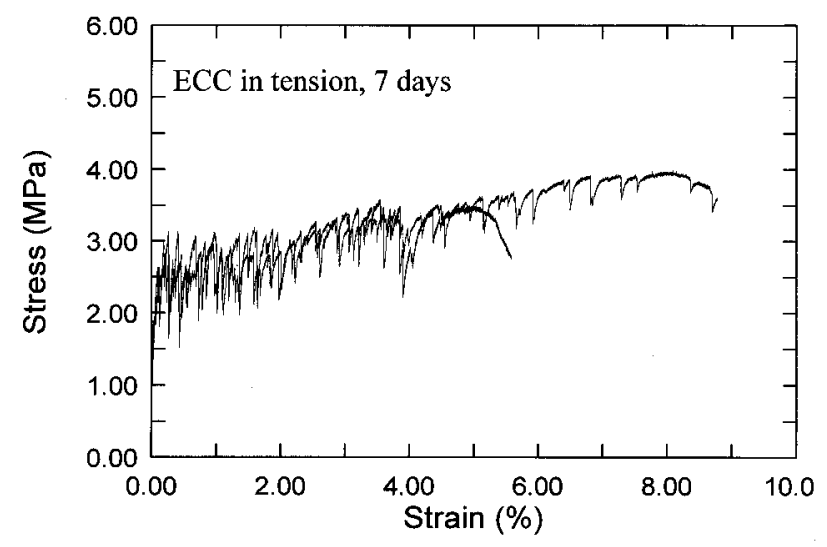

(b)

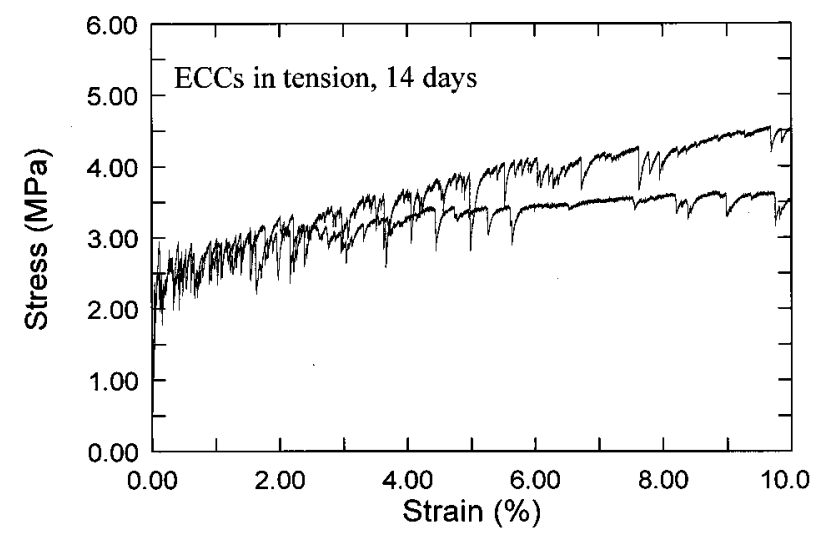

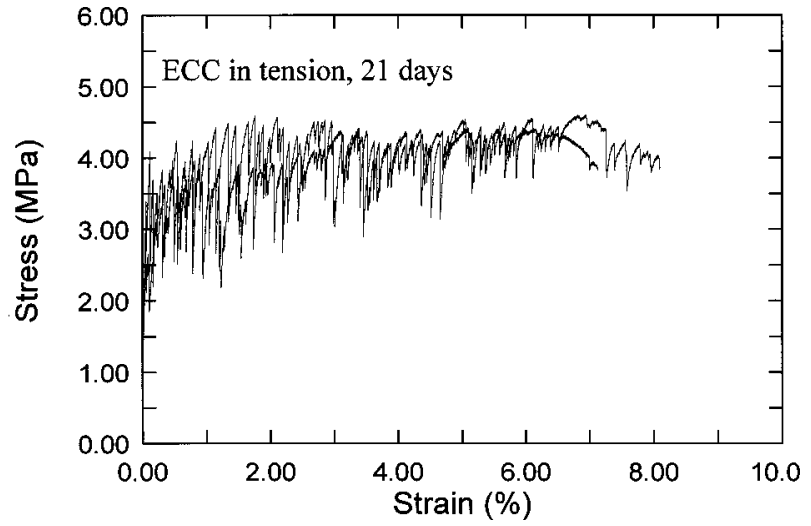

(d)

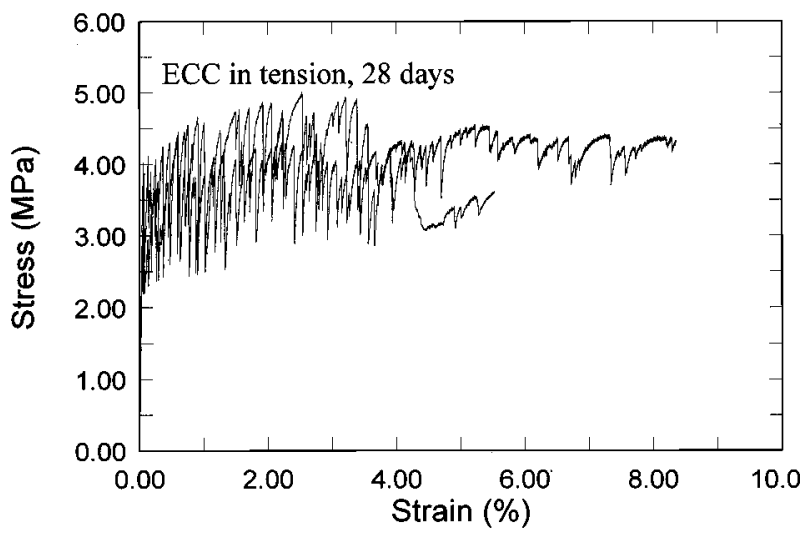

(e)

(c)

Fig. 2. Stress strain diagrams of engineered cementitious composite (ECC) in tension under different curing period, 3-28 days water curing

material after 3 days and to overtake the ultimate tensile strength of ECC after about 14 days. This means that, after a certain curing period, first cracking will occur in ECC material instead of in concrete for a specimen composed of ECC sandwiched between plain concrete sections with the same geometric dimensions, under uniaxial tensile load. These material characteristics are the basic requirements for the ductile strip design in this research. A comparison between typical plain concrete and ECC material in terms of tensile stress strain curve at 28 days water curing is shown in Fig. 6. It clearly indicates the contrasting tensile characteristics of plain concrete and ECC. The plain concrete has a high tensile strength with a low strain capacity while the ECC has a high strain capacity with a low tensile strength.

\section{Design of Concrete Slab with Ductile Strips}

The concept of placing the ECC ductile strips in a concrete slab element such as bridge decks and pavement is to fully utilize the multiple cracking and strain-hardening behavior as well as the high strain capacity of the ECC material, thus minimizing or even eliminating any damage in adjacent concrete material. The basic principle and design method of ECC/concrete interface will be described in this section.

\section{Principle}

Assume that a concrete bar is composed of two kinds of materials, ECC material and plain concrete with lengths $l_{I}$ and $l_{I I}$, 


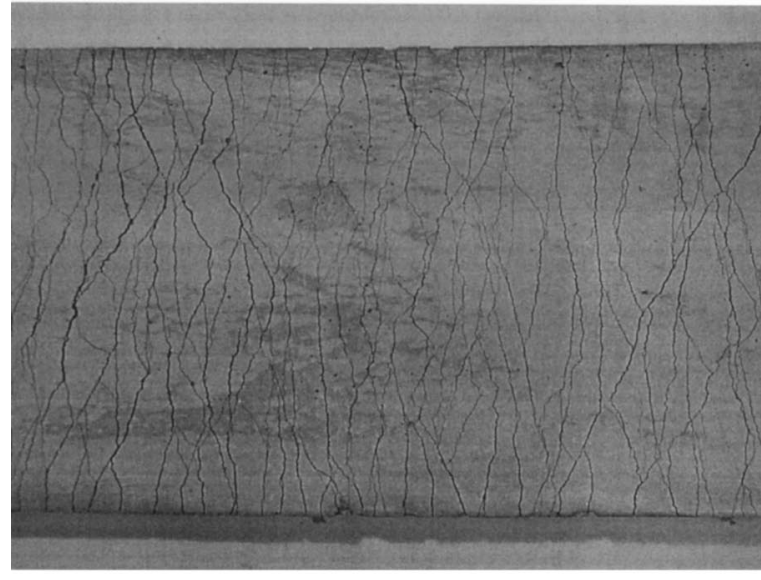

(a)

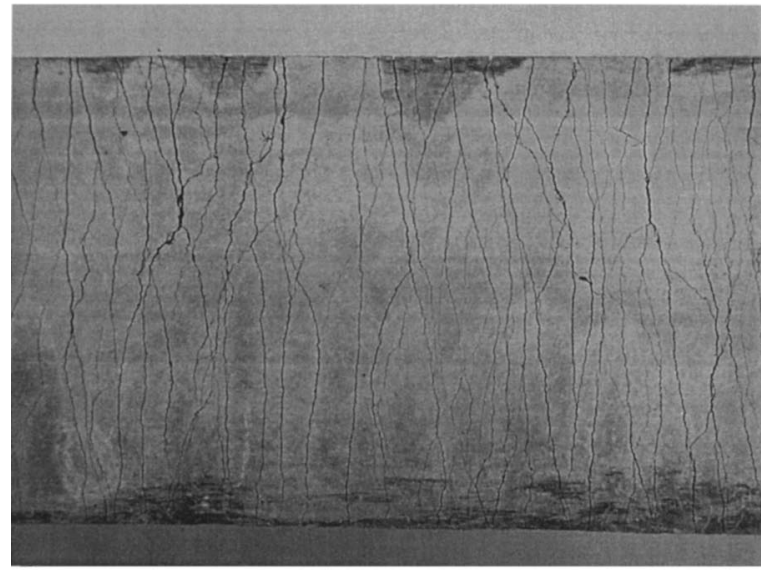

(b)

Fig. 3. Typical final crack patterns of engineered cementitious composite in tension: (a) 14 days; (b) 28 days

respectively. The bar has the same cross section along the length. Further assume that the two materials are perfectly joined together without failure at the interface under tensile load. The general dimension of the bar and the corresponding stress-strain relationship under tensile load of the individual materials are shown in Fig. 7, where the concrete tensile strength is higher than that of ECC. Under uniaxial tension, the overall strain capacity of the bar, $\varepsilon_{c}$, is reached when the load reaches the tensile strength of ECC. Hence, $\varepsilon_{c}$ is

$$
\varepsilon_{c}=\varepsilon_{I}\left(\frac{l_{I}}{l}\right)+\varepsilon_{I I}\left(\frac{l_{I I}}{l}\right)
$$

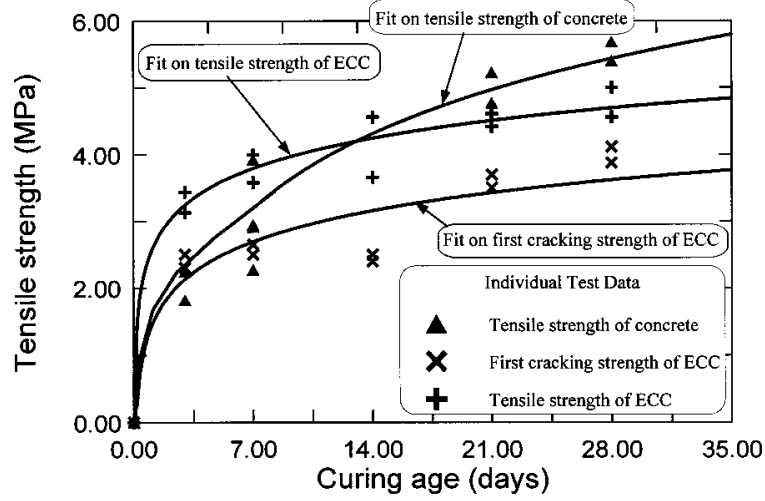

Fig. 4. Strength development with curing time of plain concrete and engineered cementitious composite material in uniaxial tension

where $\varepsilon_{I}=$ strain capacity of ECC; and $\varepsilon_{I I}=$ strain value of plain concrete corresponding to the tensile strength of ECC. $l$ is the total length of the bar. Therefore, the composite strain capacity, $\varepsilon_{c}$ (strain at peak stress in curve labeled I-II in Fig. 7), is a function of $\varepsilon_{I}, \varepsilon_{I I}$ and $l_{I}$ or $l_{I I}$. For given material properties, $\varepsilon_{c}$ is influenced only by the individual element length $l_{I}$ or $l_{I I}$. Fig. 8 demonstrates the overall strain capacity $\varepsilon_{c}$ as a function of $l_{I}$ with a different given strain capacity of ECC, $\varepsilon_{I}$. It clearly shows that, for a given ECC element length, the higher the strain capacity of ECC, the higher the overall strain capacity of the composite bar. In addition, a high composite strain capacity can also be obtained through adjusting the length of the ECC strip. With a reasonable combination of plain concrete and ECC strips, it is possible to achieve a prescribed strain capacity requirement that may be twenty or thirty times the strain capacity of plain concrete without a loss of load-carrying capacity. In this case, cracking can be avoided within the plain concrete section when the structure is subject to tensile stress, such as shrinkage stress. Instead, the ECC strip "plastically" yields to accommodate the imposed strain.

\section{Design of Engineered Cementitious Composite/ Concrete Interface}

The conventional concept of the interface in concrete and its structures normally refers to the contact area between two materials with significantly different material properties, such as mortar-aggregate interfaces, cement matrix-fiber interfaces, and new concrete-old concrete interfaces. In the present study, ECC and plain concrete can be considered as two kinds of cementitious materials with different performance, as described above. Thus, their contact area should be considered as a kind of interface. However, as both materials are cast at the same time (hot joining), the ECC/concrete interface performance should be different from

Table 3. Summary of Tensile Test Results of Plain Concrete and Engineered Cementitious Composite (ECC)

\begin{tabular}{|c|c|c|c|c|c|}
\hline \multirow[b]{2}{*}{$\begin{array}{l}\text { Time } \\
\text { (days) }\end{array}$} & \multicolumn{2}{|c|}{$\mathrm{PC}$} & \multicolumn{3}{|c|}{ ECC } \\
\hline & $\begin{array}{l}\text { First Crack Strength } \\
(\mathrm{MPa})\end{array}$ & $\begin{array}{l}\text { Ultimate Tensile Strength } \\
(\mathrm{MPa})\end{array}$ & $\begin{array}{l}\text { First Crack Strength } \\
(\mathrm{MPa})\end{array}$ & $\begin{array}{l}\text { Ultimate Tensile Strength } \\
(\mathrm{MPa})\end{array}$ & $\begin{array}{c}\text { Ultimate Tensile Strain } \\
\text { (average } \%)\end{array}$ \\
\hline 3 & - & $2.25,1.82$ & $2.30,2.50$ & $3.44,3.13$ & 5.25 \\
\hline 7 & - & $2.91,3.93,2.94$ & $2.50,2.65$ & $4.00,3.58$ & 6.5 \\
\hline 14 & - & - & $2.40,2.50$ & $4.56,3.66$ & 7.8 \\
\hline 21 & - & $5.22,4.77$ & $3.70,3.50$ & $4.42,4.61$ & 6.5 \\
\hline 28 & - & $5.40,5.68$ & $4.12,3.88$ & $4.56,5.00$ & 5.5 \\
\hline
\end{tabular}



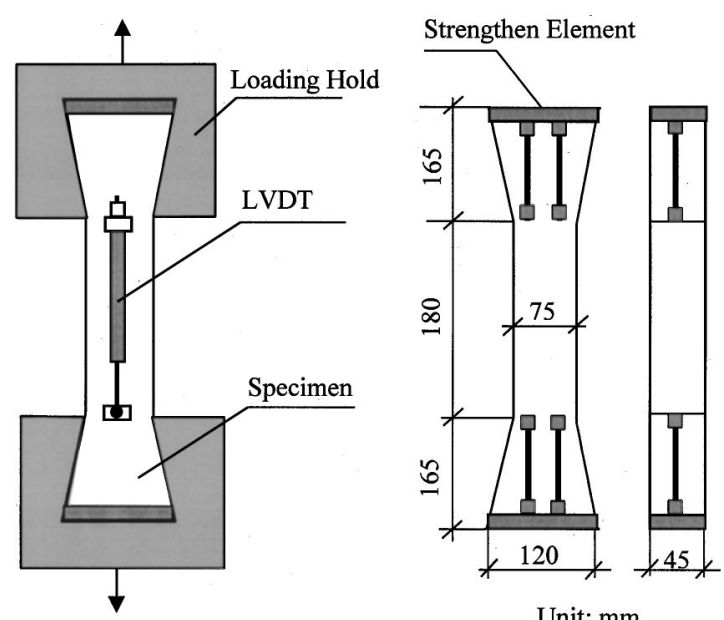

Unit: $\mathrm{mm}$

Fig. 5. Test setup and geometry of specimen of plain concrete in tension

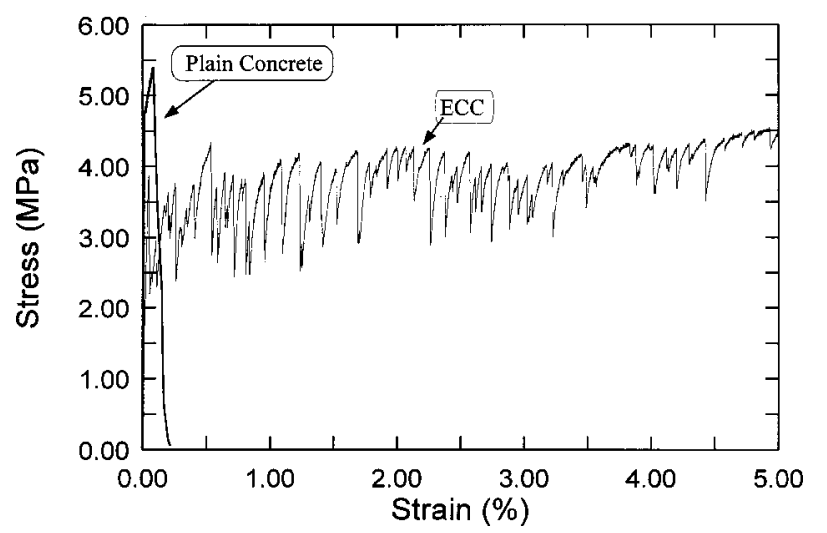

Fig. 6. Comparison on typical tensile behavior of plain concrete and engineered cementitious composite

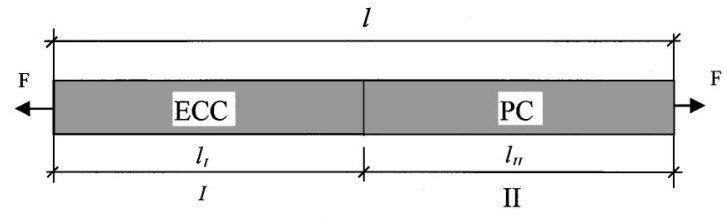

(a)

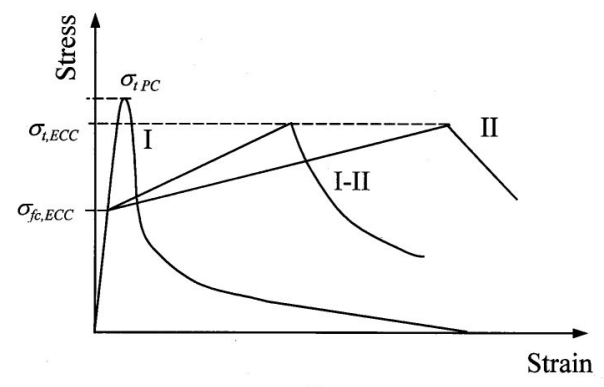

(b)

Fig. 7. (a) Engineered cementitious composite (ECC)/PC tensile bar; (b) schematic stress-strain behavior of ECC and concrete bar under uniaxial tensile load

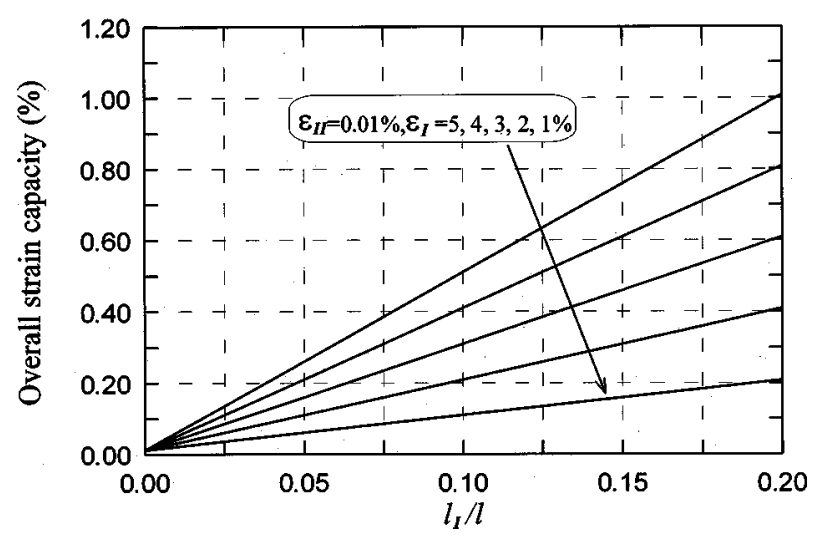

Fig. 8. Overall strain capacity of engineered cementitious composite (ECC)-concrete composite bar as function of ECC strip length, $l_{I}$

the case when the two materials are cast at different times (cold joining). The weak link between the two materials can be prevented in the former case due to the mixing effect in both materials in the plastic state. However, it is still necessary to design the ECC/concrete interface to ensure that damage under tensile stresses occurs inside the ECC strip instead of at the interface area. If first cracking occurs at or close to the ECC/concrete interface, the multiple cracking phenomenon cannot be developed due to the "fiber-end" effect at the interface area; i.e., the fiber bridging is weak at the interface area. Therefore, the present interface design principally overcomes the fiber-end effect along the ECC/concrete interface. In this study, a geometrical method to enhance the ECC/concrete interface will be applied.

Fig. 9 demonstrates the idea of the ECC/concrete interface geometric design. From stress element analysis at interface, the normal and shear stresses at interface, $\sigma_{t}$ and $\tau_{s}$, are given by

$$
\begin{gathered}
\sigma_{t}=\sigma \sin ^{2}(\phi) \\
\tau_{s}=\frac{1}{2} \sigma \sin (2 \phi)
\end{gathered}
$$

where $\sigma=$ overall tensile stress acting on the slab; and $\phi=$ angle between ECC/concrete interface and horizontal line. From Eq. (2), we can see that the normal stress $\sigma_{t}$ is a function of $\phi$ for a given stress level $\sigma$. Fig. 10 shows the relationship between the interfacial normal stress and the angle $\phi$ under some typical stress levels. $\sigma_{t}$ is reduced significantly by lowering the angle $\phi$. This indicates that it is possible to prevent interfacial failure with a reasonable interfacial angle for a given interfacial tensile strength. For example, for hot joining, the general interfacial tensile strength should be equal to the minimum value of the tensile strength of concrete and the first crack strength of ECC. Therefore, this interfacial tensile strength at least can achieve 2-3 $\mathrm{MPa}$ after 28 days curing. In this case, as $\phi$ is selected to be less than $38^{\circ}$, interfacial failure can still be prevented even as $5 \mathrm{MPa}$ over-

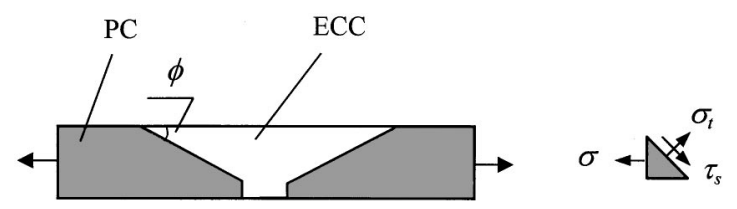

Fig. 9. Engineered cementitious composite (ECC)/concrete interface geometric design 


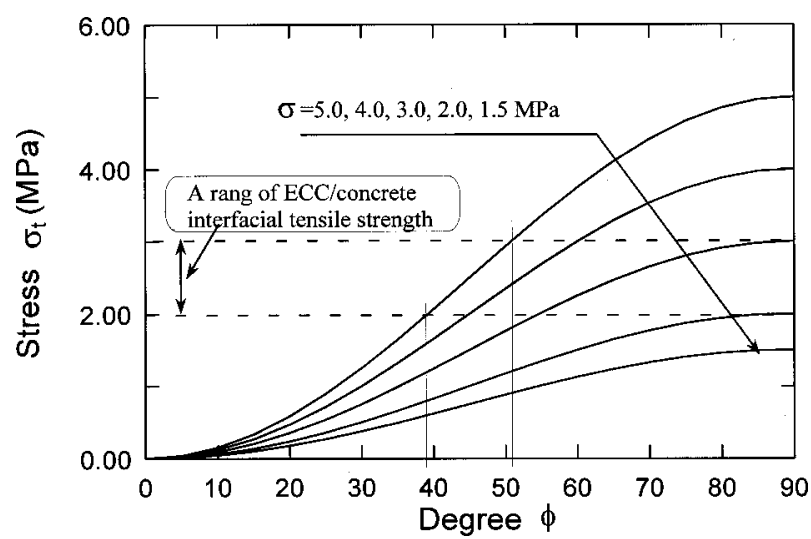

Fig. 10. Influence of interfacial angle $\phi$ on normal stress at engineered cementitious composite (ECC)/concrete interface

all stress is acting on the structure, since the interfacial tensile stress is less than $2 \mathrm{MPa}$. On the other hand, the tensile strength of ECC material is normally less than $5 \mathrm{MPa}$, as shown in Table 3 . Therefore, the above selection of $\phi$, i.e., $38^{\circ}$, is still conservative.

\section{Preliminary Experiments on Engineered Cementitious Composite Strip Design}

In this section, the validity of the above plastic strip concept will be experimentally verified through uniaxial tensile test on ECCconcrete composite specimen. In the present work, a $30^{\circ}$ interface

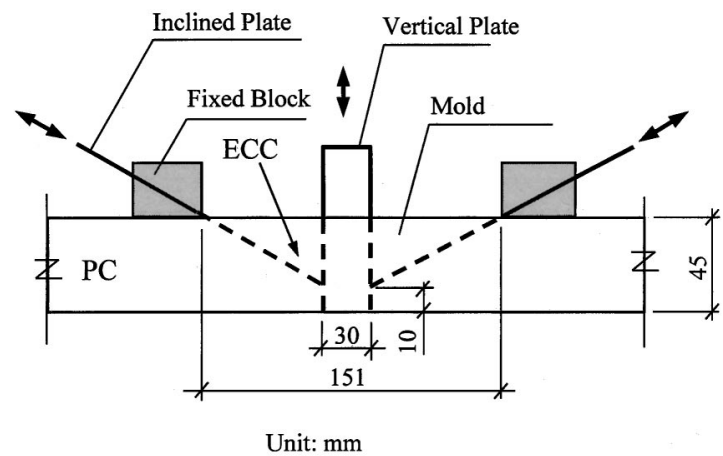

(a)

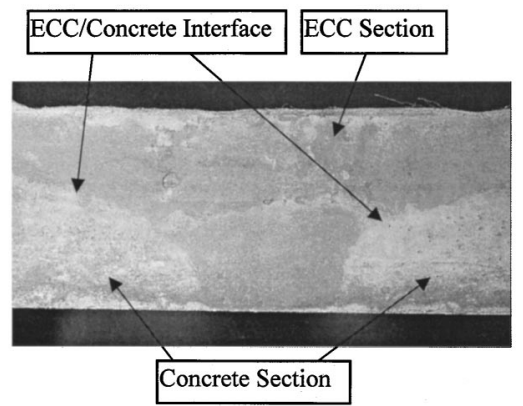

(b)

Fig. 11. (a) Casting device for inclined engineered cementitious composite/concrete interface; (b) view of specimen after casting (ECC has a slightly darker color than concrete)

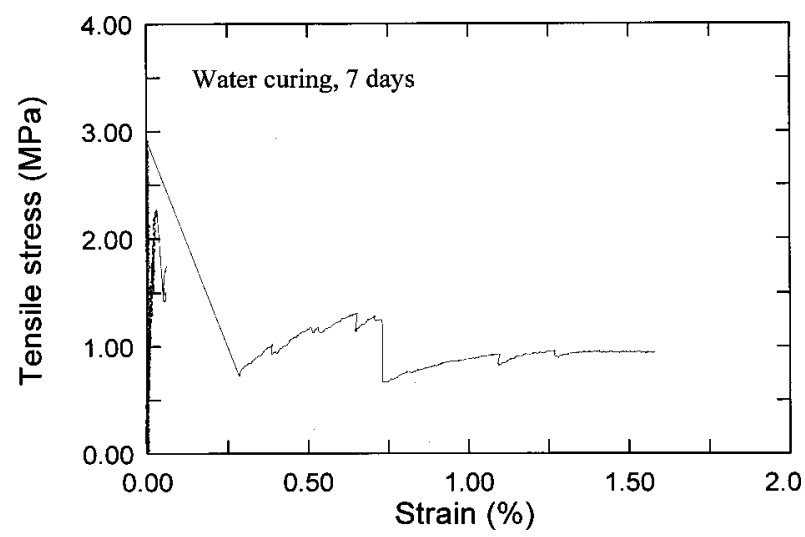

(a)

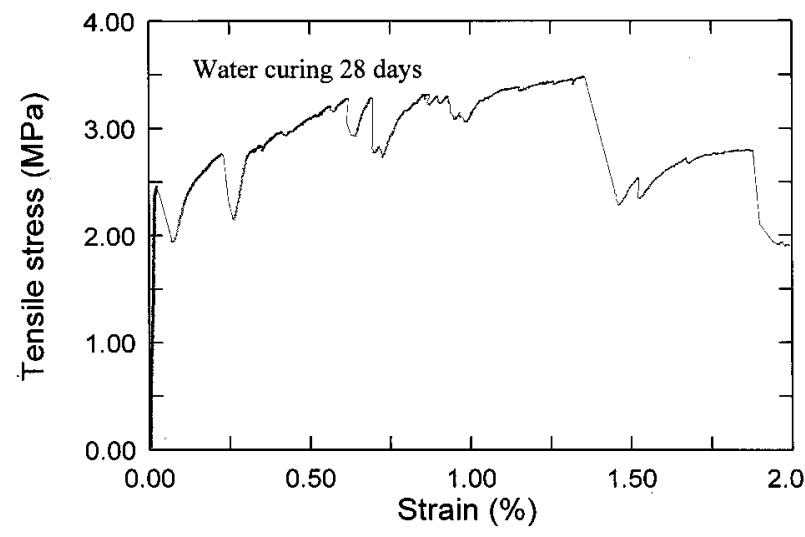

(b)

Fig. 12. Tensile stress strain performance of engineered cementitious composite-concrete composed specimen for different curing periods; (a) 7 days; (b) 28 days

angle was adopted. The same size of specimen as used in uniaxial tensile tests of plain concrete, as shown in Fig. 5, is used in these experiments.

\section{Specimen Preparation}

In order to cast the concrete sections and the ECC strip at the same time and to ensure an inclined angle of $30^{\circ}$ for the ECC/ concrete interface, a special casting device was developed, as shown in Fig. 11(a). The device consists of two vertical movable steel plates and another two movable steel plates that can slide along the direction with a prescribed inclined angle. This is realized by fixing two polymeric foam blocks with a path for sliding of the steel plate along the designed angle. The width of the steel plates is fixed to the mold width. The polymeric foam blocks were fixed at the top of the mold by glue.

The specimen casting procedure can be described as follows. First, with the vertical and inclined steel plates in place, the fresh concrete and ECC are carefully cast into the plexiglass mold to form a $10 \mathrm{~mm}$ thick layer. Then the mold is vibrated for about half a minute. Next, the vertical steel plate is gradually raised until out of the layer with the vibrating table running. Concrete and ECC are then poured into the respective sections to fill out the rest of the mold. The specimen is further vibrated and attention is paid to all corners of the mold until no more air comes out. Then, the inclined steel plates are slowly pulled out of the mold. During movement of the plate, the vibrating table is kept running 


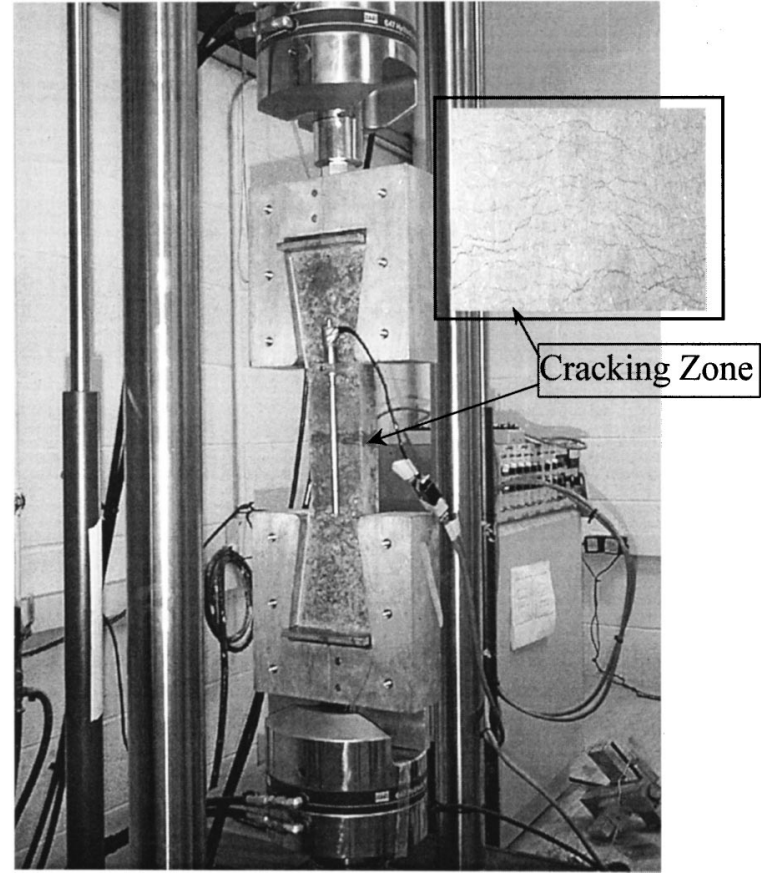

Fig. 13. View of cracking in engineered cementitious composite (ECC) strip of ECC-concrete composite specimen (close-up view of cracking zone shown in insert)

to prevent induction of air. After that, vibration is continued for another minute. After smoothing the surface, the specimens are covered with a polyethylene sheet and stored for $24 \mathrm{~h}$ at room temperature. Then the specimens are removed from their molds and put into water at $23^{\circ} \mathrm{C}$ for curing until the date of testing. The overview of the specimen after casting is shown in Fig. 11(b).

\section{Results and Discussion}

The above tensile specimens were tested at 7 days and 28 days after casting, respectively. The test procedure was the same as that used for the tensile test on plain concrete. The tensile test results on the specimens with ECC strip are shown in Figs. 12(a and b) in terms of tensile stress versus strain diagrams. From these results, we can see that, for the specimen cured only for 7 days, the specimen failed in a brittle manner even though the first crack already occurred in the ECC strip in one of the two specimens. However, the final failure occurred in the concrete section of this specimen. This is expected, since at 7 days curing the first crack strength of ECC and the tensile strength of plain concrete are very close; see Fig. 4. Therefore, even if the first cracking occurs in the ECC strip, as load increases, the stress in the concrete section may reach the concrete tensile strength, resulting in failure in the concrete section instead of further development of new cracks in the ECC strip.

For the specimen cured for 28 days, the situation is totally different. In this case, the concrete tensile strength is much higher than the first crack strength of ECC and even higher than the ultimate tensile strength of ECC. Therefore, as the specimen is loaded in tension, first cracking will occur in the ECC strip and multiple cracking can be developed in it due to sufficient difference between the ultimate tensile strengths of ECC and concrete. As a result, the tensile behavior shown in Fig. 12(b) is obtained. Cracking with crack widths less than $0.1 \mathrm{~mm}$ was successfully localized into the ECC strip instead of in the concrete section.
This is the final goal of the present investigation. Furthermore, in the present dimension of the specimen, the strain attained $1.4 \%$ at peak load $(3.5 \mathrm{MPa})$. A view of the specimen after cracking in ECC section is shown in Fig. 13.

\section{Conclusion and Future Work}

This paper presents an experimental study on the potential applications of fiber-reinforced engineered cementitious composite in continuously steel reinforced concrete slabs, such as concrete bridge decks and pavement, for the purpose of eliminating cracks in concrete. It is found that a composite slab containing both plain concrete and ECC strips, with proper design at the ECC/concrete interfaces and careful selection of material properties (i.e., to assure that the tensile strength of concrete higher than that of ECC material), it is possible to localize tensile cracks into the ECC strip instead of in the concrete section. The current concrete mix satisfies the above condition after 14 days of water curing. Due to the strain-hardening performance of the ECC material with a high strain capacity (up to 5\%) as well as a high fatigue crack resistance behavior, the overall strain capacity and the integrity as well as the fatigue durability of the composite slab can be significantly improved. In the present study, the overall strain capacity of the test specimen achieves $1.4 \%$ at peak load.

Further experiments with larger scale specimens are needed in order to apply the design concept explored in the present work to more realistic field situations. The present investigation does not involve continuous steel reinforcement. However, it is expected that the inclusion of steel reinforcement will further enhance the ductile strip concept explained in this study.

\section{Acknowledgment}

This work has been supported by a grant from the National Science Foundation (CMS-9872357) to the Univ. of Michigan.

\section{References}

Chan, Y. W., and Li, V. C. (1997). "Age effect on the characteristics of fiber/cement interfacial properties." J. Mater. Sci., 32(19), 52875292.

Kanda, T., and Li, V. C. (1998). "Multiple cracking sequence and saturation in fiber reinforced cementitious composites." Concr. Res. Technol., 9(2), 1-15.

Kumar, S. V., and GangaRao, H. V. S. (1998). "Fatigue response of concrete decks reinforced with FRP rebars." J. Struct. Eng., 124(1), $11-16$.

Li, V. C. (1993). "From micromechanics to structural engineering-the design of cementitious composites for civil engineering applications." J. Struct. Mech. Earthquake Eng., 10(2), 37-48.

Li, V. C. (1998). "Engineered cementitious composites-tailored composites through micromechanical modelling." Fiber-reinforced concrete: present and the future, N. Banthia, A. Bentur, and A. Mufti, eds., Canadian Society for Civil Engineering, Montreal, 64-97.

Li, V. C., Wu, H. C., Maalej, M., and Mishra, K. (1996). "Tensile behavior of cement-based composites with random discontinuous steel fibers." J. Am. Ceram. Soc., 79(1), 74-78.

Matsui, S. (1997). "Technology developments for bridge decksinnovations on durability and construction." Kyouryou To Kiso, 97(8), 84-92 (in Japanese). 
Perdikaris, P. C., and Beim, S. (1988). "R/C bridge decks under pulsating and moving load." J. Struct. Eng., 114(3), 591-607.

Perdikaris, P. C., Beim, S. R., and Bousias, S. N. (1989). "Slab continuity effect on ultimate and fatigue strength of reinforced concrete bridge deck models." ACI Struct. J., 86(4), 483-491.

Szerszen, M. M., Nowak, A. S., and Kwasniewski, L. J. (1999). "Devel- opment of the procedure for efficient evaluation of bridge decks." Rep. No. 99-14, Civil Engineering Dept., Univ. of Michigan, Ann Arbor, Mich.

Wu, H. C., and Li, V. C. (1994). "Trade-off between strength and ductility of random discontinuous fiber reinforced cementitious composites." J. Cement Concr. Compos., 16(1), 23-29. 